\title{
Bleeding to Life: A Case Series of Hematohidrosis and Hemolacria
}

\author{
Debaditya Das $^{1}$ (D) $\cdot$ Priyanka Kumari $^{1} \cdot$ Avishek Poddar $^{1} \cdot$ Tamal Laha $^{1}$
}

Received: 31 March 2019 / Accepted: 4 September 2019 / Published online: 16 September 2019

(C) Dr. K C Chaudhuri Foundation 2019

To the Editor: Hematohidrosis, although a rare clinical entity, is well documented in medical literature. It may be accompanied with blood in tears or bloody otorrhoea [1]. We present two cases of hematohidrosis and hemolacria.

Case 1: A 15-y-old female child presented with profuse bleeding from the ears, nose and eyes since last $2 \mathrm{wk}$ following a head injury. Otoscopy, endoscopic examination of the nose and throat and upper GI endoscopy did not show any signs of trauma or source of bleeding.

Case 2: A 13-y-old female child presented to our emergency with complaint of bleeding from the face, eyes, shoulders and forearm since $1 \mathrm{~h}$ back. On further enquiry it was found that these attacks of 'bleeding' were preceded by anxiety symptoms and had been happening for last $2.5 \mathrm{mo}$.

In both the cases, blood counts, coagulation tests (including thromboelastogram), biochemical tests and skin biopsy were within normal limits. Microscopy of the fluid revealed presence of red and white blood cells, platelet clumps and mucus. Psychiatric opinion was sought and they were started on anxiolytics and propranolol. In the first case the symptoms reduced but did not stop and in the second case the child got symptom free.

It is hypothesized, that during severe stress there is cutaneous vasoconstriction due to sympathetic overdrive followed by rebound vasodilation and rupture into the sweat glands causing the blood to mix with the sweat [2]. One case report has attributed platelet factor-3 dysfunction as a cause [3]. Trauma to the head can be a precipitating factor for these events [4]. Chromhidrosis can be ruled out by observing cellular elements of the blood in sweat. Henoch-schönlein purpura should be ruled out by doing a skin biopsy. Possibility of malingering can be ruled if the episodes are witnessed by any hospital staff. Controlling the anxiety symptoms has been shown to resolve the bleeding. Case reports are there, where beta blockers have been used with success [5]. In our cases, we had used propranolol and were successful in controlling symptoms in one and decreasing the symptoms in the other.

\section{Compliance with Ethical Standards}

Conflict of Interest None.

\section{References}

1. Tshifularo M. Blood otorrhea: blood stained sweaty ear discharges: hematohidrosis; four case series (2001-2013). Am J Otolaryngol. 2014;35:271-3.

2. Jerajani HR, Jaju B, Phiske MM, Lade N. Hematohidrosis- a rare clinical phenomenon. Indian J Dermatol. 2009;54:290-2.

3. Mishra KL. Bloody tears and hematohidrosis in a patient of PF3 dysfunction: a case report. Cases J. 2009;2:9029.

4. Yeșilova Y, Turan E, Aksoy M. Hematidrosis on the forehead following trauma: a case report. Int J Dermatol. 2017;56:212-4.

5. Wang Z, Yu Z, Su J, et al. A case of hematidrosis successfully treated with propranolol. Am J Clin Dermatol. 2010;11:440-3.

Publisher's Note Springer Nature remains neutral with regard to jurisdictional claims in published maps and institutional affiliations.

Debaditya Das

dasdebaditya@yahoo.com 